\title{
apontaCursos: um Sistema Web para Gerenciar Informações sobre Palestras, Treinamentos e Eventos
}

\author{
Pablo Bizzi Mahmud ${ }^{1}$, Marcia Pasin ${ }^{2}$ \\ ${ }^{1}$ Departamento de Computação - Universidade Federal de São Carlos (UFSCar) \\ Km 235 Washington Luís \\ São Carlos, São Paulo - SP - Brasil \\ ${ }^{2}$ Centro de Tecnologia - Universidade Federal de Santa Maria (UFSM) \\ Av. Roraima 1.000 - Cidade Universitária - Santa Maria - RS - Brasil \\ pablo.mahmudedc.ufscar.br, marciadinf.ufsm.br
}

\begin{abstract}
Due to the growing demand of training courses and the lack of a website where clients and advertisers can easily find each other, in this work, we proposed a portal to fill this gap. We developed website to allow the access to training courses, centralizing information about lectures and other events. The website provides, in academic and business fashion, the approaching between advertisers and interested public. The main result of this work is a service where people can make the registration and the search of those professional training services, so that users are able to meet their needs.
\end{abstract}

Resumo. Devido à crescente busca de cursos e treinamentos visando qualificação por parte do público consumidor e falta de um website onde a conexão entre consumidor e anunciante fosse facilitado, foi vislumbrada a possibilidade de desenvolver um portal que conseguisse abastecer essa lacuna nos nossos meios de comunicação de serviços. A partir dessa problemática, foi desenvolvido um website para facilitar o acesso à qualificação profissional, centralizando informações sobre palestras, cursos, eventos. O Website proporciona, nos meios acadêmicos e empresariais, aproximar anunciantes e público interessado. $O$ principal resultado do trabalho foi a confecção de um Website onde é possível realizar o cadastro e a busca desses serviços de qualificação profissional para que os usuários consigam satisfazer suas necessidades.

\section{Introdução}

O mercado está cada vez mais competitivo e existe necessidade por parte dos profissionais de buscar contínua atualização. Em paralelo à esta demanda, existe também uma gama crescente de instituições e empresas que oferecem cursos de aperfeiçoamento. A educação e a qualificação da mão de obra são um impacto no que tange o empreendedorismo social, conceito-chave para o motor econômico de qualquer nação.

Atualmente existem numerosas ofertas de palestras, treinamentos e eventos, e normalmente usuários utilizam ferramentas como Adwords e Adsenses do Google, disparam diversas Newsletters e fazem parceria com blogs para a divulgação. A disseminação de informações é voltada a profissionais e empresas há mais tempo no mercado, que buscam 
alcançar novos mercados de uma forma não muito conturbada. Normalmente, algum resultado é obtido. Porém, o trabalho é realizado de forma não automatizada, e o retorno pode não compensar o investimento, visto que para conseguir o êxito, o investimento pode acabar sendo destinando para mais de uma empresa publicitária ou necessitar de uma equipe própria da empresa.

A necessidade das empresas exporem seus serviços, aliada a outras necessidades como demanda por informação, demanda por acesso a redes sociais, etc. torna a web um universo extremamente abrangente, o que gera um problema: Como encontrar tudo e exatamente o que se deseja? Ferramentas de busca, como Google realmente encontram tudo ou encontram exatamente o que é necessário sobre um assunto mais complexo?

Portais de buscas dinâmicas são vastamente utilizados [1], mas ocasionalmente não sanam a busca de um usuário. Em alguns casos, é necessário um portal específico para realizar alguma atividade. Este cenário motivou o desenvolvimento de um portal para facilitar o acesso à qualificação profissional, e que centraliza informações sobre palestras, cursos, eventos, reunindo o perfil dos organizadores dessas atividades.

A web vem obtendo cada vez mais espaço na participação das atividades rotineiras dos usuários de sistemas computacionais. Em muitos casos, sua utilização é indispensável, principalmente em meios educacionais. Análises podem ser realizadas para mensurar e, consequentemente, satisfazer as necessidades dos usuários [5].

Um problema encontrado ao utilizar o sistema do Google é a quantidade de publicidade encontrada, em contrapartida o sistema apresentado por trabalho não possui anúncios. Os anúncios são encontrados na forma de advertisements ou em uma melhor colocação nos resultados da busca. Por exemplo, digitando a busca "curso de php santa maria rs", os primeiros resultados encontrados não são fidedignos ao que realmente fora buscado.

O sistema web resultante deste trabalho é denominado apontaCursos. O apontaCursos é como um motor de busca que auxilia na obtenção de informações armazenadas na rede mundial World Wide Web, dentro de um sistema distribuído, em uma rede corporativa ou de um computador pessoal. O sistema permite que usuários solicitem informação sobre um evento ou palestra, a partir de um critério específico e retorna a partir de um padrão estabelecido as informações que combinam com tal critério.

Este texto está organizado como segue. A seção 2 apresenta o detalhamento do projeto da ferramenta desenvolvida. A implementação é descrita na seção 3. Por fim, a seção 4 apresenta conclusões e trabalhos futuros.

\section{Metodologia}

Para que os objetivos deste trabalho fossem cumpridos, foi previsto um conjunto de atividades. Essas atividades foram definidas visando o desenvolvimento ágil do projeto, as quais podemos visualizar nas seçẽs a seguir.

\subsection{Análise de Requisitos e Análise de Tarefas}

As interfaces gráficas surgiram na década de 1980, substituindo as interfaces de texto, até então dominantes, onde o usuário interagia com o computador por meio de comandos

\footnotetext{
${ }^{1}$ http://www.google.com 
escritos, o que dificultava a sua utilização por pessoas leigas, devido à necessidade de decorar estes comandos e ainda conhecer todas as suas particularidades.

Uma interface inspira sentimentos de rejeição e aceitação que determinam a maneira como o usuário irá se comportar diante de um sistema computacional. Sabe-se que muitas pessoas que decidem abandonar o uso de um programa, porque não sabem esperar [2]. Por isso, conclui-se que a familiarização imediata de um usuário com o sistema baseia-se ter um layout amigável e interativo (ver outras demandas em [3]). Portanto, é necessário conhecer o perfil dos usuários, e com isso são descobertas suas necessidades, capacidades e limitações.

O projeto de uma interface para um perfil de usuário muito heterogêneo, como representa-se o público-alvo deste projeto, é um desafio e requer satisfazer com eficiência as necessidades funcionais.

Com o objetivo de determinar o perfil dos usuários do portal, optou-se por seguir a análise de tarefas dos usuários, sejam eles Compradores ou Anunciantes. Foi traçado também o público-alvo do sistema, definindo assim a melhor forma de abordagem, visto que o público engloba todas as áreas de conhecimento e ampla faixa etárias.

A partir das definições citadas por [4], o método mais relevante para levantar requisitos que permite uma análise cuidadosa e abrangente, é a utilização de questionários ou entrevistas, já que o sistema não é dedicado a um cliente específico mas é um portal focado em diferentes tipos de usuários.

A técnica utilizada foi separada para os dois tipos diferentes de usuários: Anunciantes e Compradores de anúncios. O questionário foi elaborado com perguntas subjetivas, onde procurou-se captar informações sobre o que usuários esperam do sistema. Resumidamente, com a aplicação de questionários, foram obtidos resultados que influenciaram diretamente na escolha das cores e na forma de como o menu foi distribuído na interface, tal como os mecanismos de busca do sistema.

\subsection{Processos da Implementação}

Uma sequência de passos representam o sucesso da implementação. A partir das coletas de informações anteriores são realizadas as implementações e suas validações e, consequentemente, suas correções, se houver necessidade.

Além disso, sabe-se que o processo de implementação de interfaces Web envolve desenvolvimento e testes, em um processo repetitivo. Durante a confecção é necessário o feedback sucessivo de futuros usuários do sistema e do próprio desenvolvedor.

Com isso pode-se concluir que é muito importante a utilização de ferramentas adequadas para o desenvolvimento, que permitem produzir um sistema estável e que não demande um tempo excessivo.

\subsection{Especificação de tarefas dos usuários}

Para uma análise efetiva das tarefas que usuário deve executar, o analista precisa se projetar na figura do usuário. Este é um grande desafio para o desenvolvedor pois, este pode ser incapaz de detectar erros em seu próprio código. Contudo, um usuário de outra área de atuação ou de outra faixa etária pode apresentar dificuldades na utilização do sistema. Por isso a comunicação entre o cliente e o analista é essencial. É de extrema importância 
dividir as permissões dos usuários no sistema, elencando as principais funções do sistema. Nesse contexto, a Figura 1 apresenta os principais casos de uso do sistema dos usuários, que são divididos em duas categorias (Anunciante e Comprador). De fato, as funcionalidades são apresentadas de forma simplificada pois apresentam um grau enorme de complexidade. Outros casos de uso de funcionalidades incluem imprimir voucher, imprimir lista de presença, cadastrar-se, etc. Outro aspecto importante que pode ser verificado neste caso de uso, é a possibilidade de adaptação do sistema perante as ações do usuário, onde um anunciante pode, em determinado momento, tornar-se um comprador, e vice-versa.

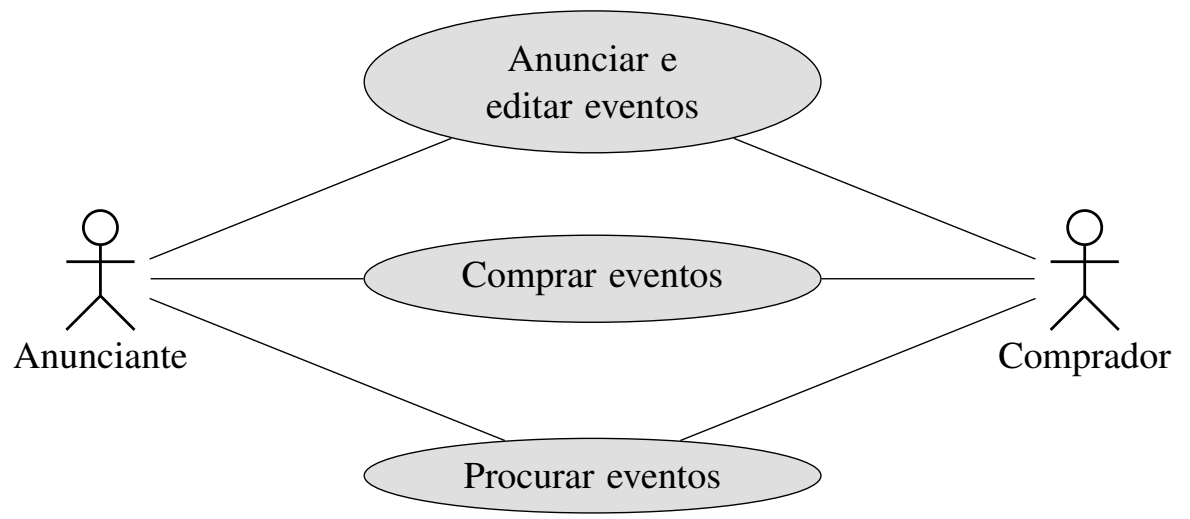

Figura 1. Casos de uso das ações dos usuários do sistema.

A partir dos questionários aplicados e de observações aos diversos portais de pesquisa que existem no mercado, foram definidas as principais atividades dos usuários, mostradas nas Figuras 2 e 3 , onde mostra cada passo que um usuário anunciante ou comprador podem realizar no portal. O questionário pode ser visualizado em: https://docs.google.com/forms/d/1_ Laf1 jWjqZyBkg0CmXLJ1575BaC0W3wP-SuO9MuCD1A/viewform.

De acordo com a Figura 2, primeiro, o usuário faz uma busca de cursos, palestra ou evento. Ao receber a resposta da busca, se houver resposta, o usuário analisa as opções e decide pela opção de compra. Se o usuário não possui conta no sistema é solicitado o cadastro, caso contrário ele é redirecionado para as opções de pagamento (via PagSeguro). Se o evento é gratuito, simplesmente é confirmada a inscrição do usuário.

De acordo com a Figura 3, primeiro, o usuário deseja cadastrar cursos, palestras ou eventos. Será solicitado que o usuário entre com sua conta no sistema, caso contrário é necessário o cadastro. Ao entrar com sua conta, o usuário utilizará a rotina para cadastro ou edição de seus eventos, se houver alguma edição, os usuários inscritos neste evento são devidamente avisados da alteração. Se o evento não é gratuito, é solicitado o cadastro dos dados bancários do anunciante para repassar o montando ao final das inscrições. Por fim, o anunciante pode imprimir a lista de inscritos para o evento.

Por fim, o sistema possui dois mecanismos de busca: a busca por palavra-chave, mostrada na Figura 4 (a) que é mais eficiente, e a busca detalhada Figura 4 (b), onde filtros específicos são adicionados para melhorar a precisão dos resultados. 


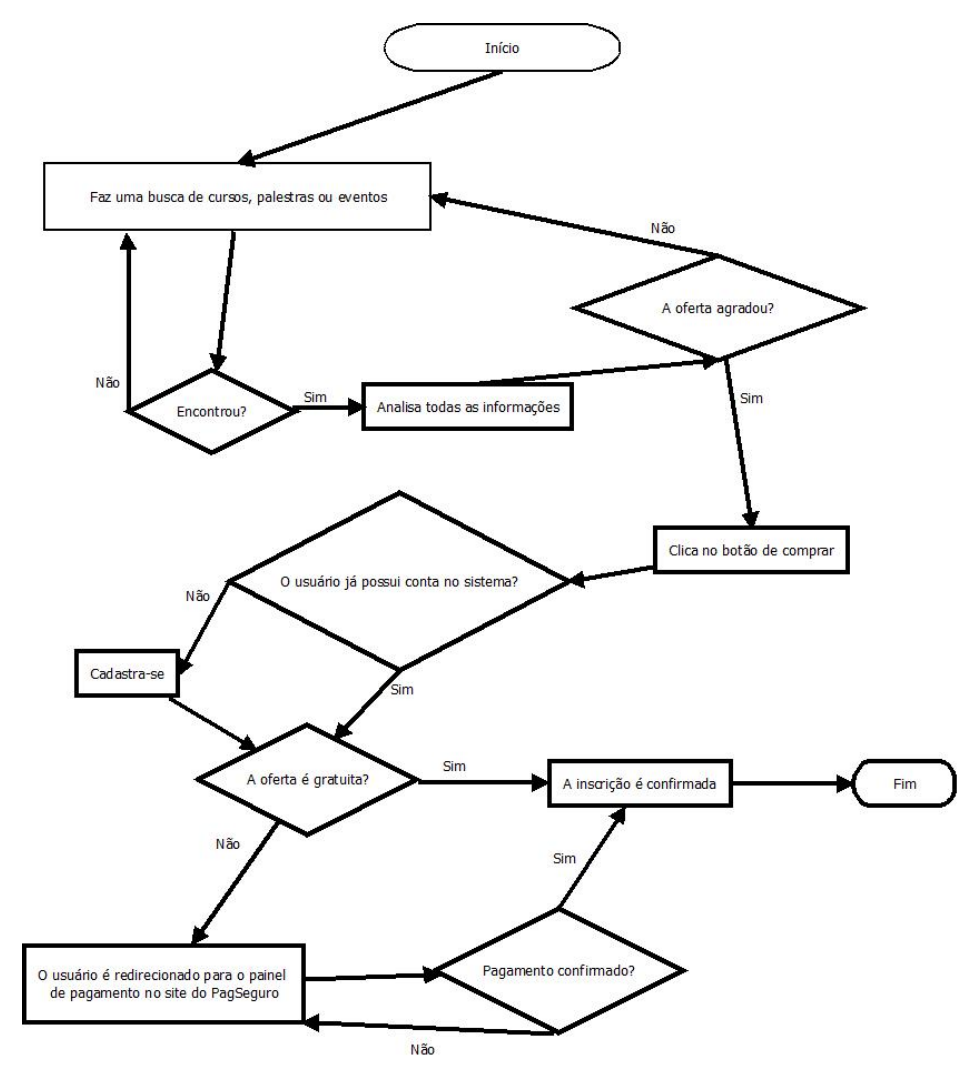

Figura 2. Fluxograma de ações do usuário comprador.

\subsection{Tecnologias para o desenvolvimento}

Neste trabalho, foram utilizadas diversas tecnologias para o desenvolvimento. Destacamse PHP e MySQL. Ainda utilizou-se tecnologias complementares para o desenvolvimento, dentre elas pode-se citar: (i) Doctrine: plugin do framework utilizado neste projeto que converte as consulta SQL, que retornam arrays, em objetos manipuláveis na controladora e na página HTML; (ii) HTML5, CSS3 e Bootstrap: utilizado para o desenho do layout do sistema, neste caso, foi desenvolvido um template responsivo; (iii) mpdf: plugin que recebe um array da controladora do framework e gera os tickets em formato $p d f$; (iv) PagSeguro: utilizado para receber os pagamentos dos tickets; e (v) CodeIgniter: utilizado para estabelecer um modelo de projeto MVC. Como essas ferramentas são complementares, acredita-se não ser necessário uma descrição mais precisa das mesmas.

\subsection{Arquitetura e comunicação}

O princípio da aplicação consiste em garantir comunicação eficiente entre usuários e banco de dados, implementados em uma arquitetura típica de cliente-servidor, e um banco de dados acoplado ao servidor. Mas especificamente, a comunicação com o banco baseiase em entrada e saída de dados. A entrada de dados pode ser definida essencialmente como cadastro de usuário e de anúncios.

As principais rotinas de saída de dados incluem: $(i)$ Buscar de cursos, palestras ou eventos; ( $i$ i ) Buscar eventos cadastrados pelo usuário visualizado em sua página de administrador tal como ingressos vendidos e outras informações; (iii) Buscar eventos comprados pelo usuário visualizado em sua página de administrador; (iv) Visualizar in- 


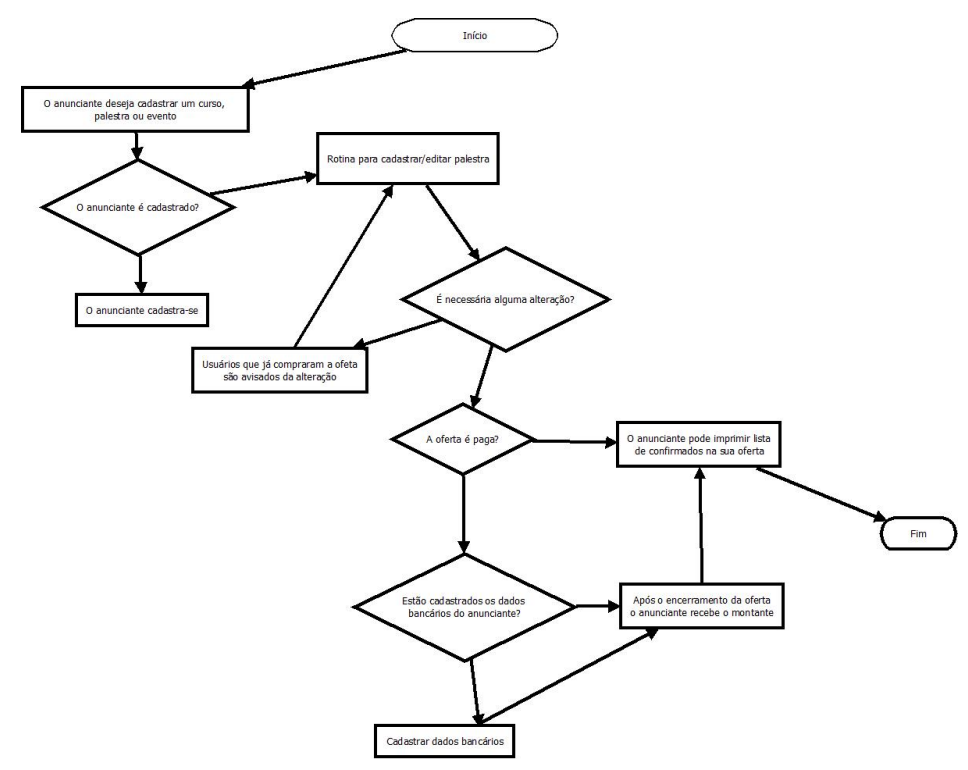

Figura 3. fluxograma de ações do usuário anunciante.

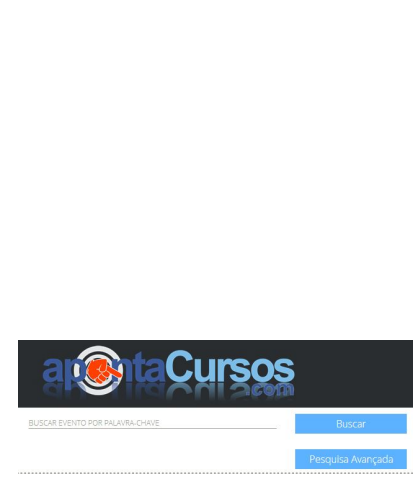

(a)

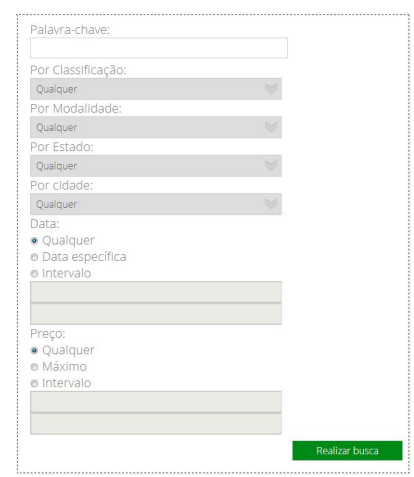

(b)

Figura 4. (a) Primeira e (b) segunda opção de mecanismo de busca.

formações de um anúncio; e $(v)$ Visualizar informações para ações publicitárias, como público-alvo e regiões mais ativas.

\subsection{Modelagem do Banco de Dados}

A modelagem do banco de dados foi realizada através do Doctrine que tem a capacidade de gerar as tabelas do sistema a partir de arquivos PHP.

As entidades do sistema totalizaram trinta e um arquivos e podem ser divididos em seis grupos, são eles: ( $i$ ) Cadastro de pessoas (físicas e jurídicas); (ii) Cadastro de anúncios; (iii) Endereços; (iv) Tickets; (v) Tags para rastreamento; e (vi) Tabelas para mapeamento de dados. Como trata-se de um sistema comercial, o diagrama de classes será omitido.

\section{Implementação}

Esta seção apresenta detalhes de implementação do portal implementado em decorrência aos objetivos deste trabalho. 


\subsection{Interface Gráfica do Portal}

Para a construção da interface gráfica do Portal, foi usado um modelo suave de cores, contrastando com fundo preto. Modelo que é utilizado por não causar transtornos para usuários com necessidades especias, tais como daltônicos. Uma captura de tela do menu é mostrada na Figura 5. Nenhuma cor usada remete sentimento de alerta ou de perigo, como exemplo do amarelo e do vermelho. As cores predominantes do sistema são tons de azul, verde e escalas de cinza. Foi escolhido o azul por preferência do desenvolvedor, já que diversos websites de sucesso utilizam o azul, como é o exemplo do Facebook . com.

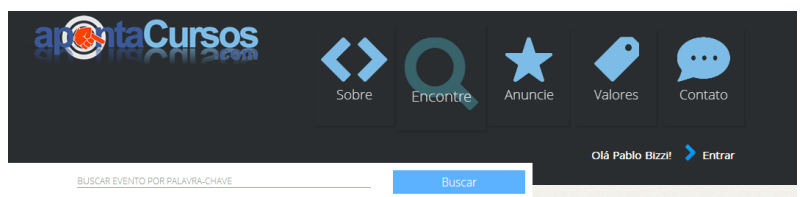

Figura 5. Menu do sistema apontaCursos

\subsection{Interação com o Usuário}

Neste trabalho, foi dedicada uma atenção especial com funcionalidades de ajuda e disponibilidade de informações. A Figura 5 mostra o primeiro contato do usuário com o sistema. O menu oferece a oportunidade de resolver as dúvidas, tendo disponíveis caminhos de acesso para valores, dúvidas para Anunciantes e Compradores, uma página para contato e um link de acesso rápido ao portal restrito a usuários cadastrados.

A barra lateral auxilia o menu superior como complemento de informações, como mostrado na Figura 6 (a). Há repetição de funcionalidades do menu além da área de imprensa e newsletter. Como complemento de funcionalidade, para usuários que não são novos no sistema, existe a opção de realizar a busca na página inicial.

\subsection{Praticidade ao Usuário}

Neste trabalho foi implementado um cadastro simples e otimizado. Para preenchimento de endereços, por exemplo, foi desenvolvido um formulário onde o usuário apenas informa o CEP e preenche o número e o complemento. O sistema busca os demais dados diretamente em um banco de dados de endereços, fornecido pelo Google. Esse método

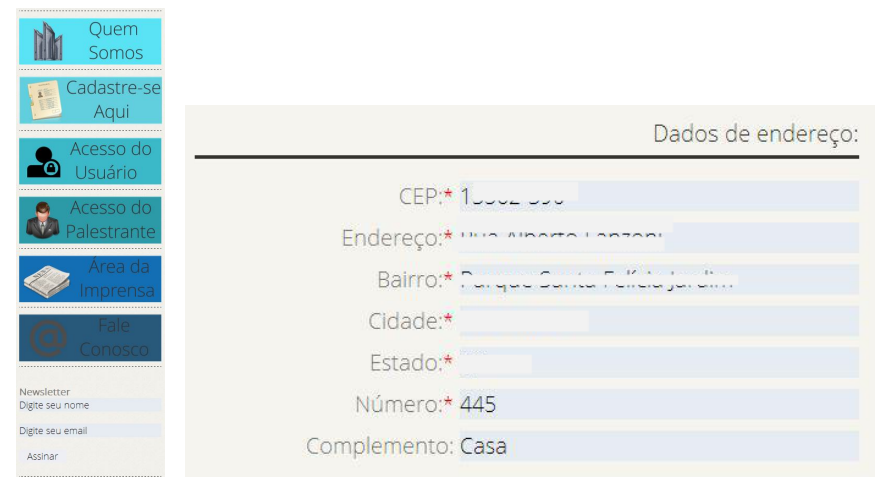

(a)

(b)

Figura 6. (a) Barra lateral do sistema servindo como complemento ao menu superior e (b) Fragmento do formulário de cadastro. 
além de ser prático, auxilia na consistência dos dados do sistema e elimina a necessidade de desenvolver uma consulta mais complexa em SQL. Uma vez que não há diferença nos dados, por exemplo, um usuário preenche a sigla do estado com RS ou com $r s$. Um exemplo deste formulário é mostrado na Figura 6 (b).

Outro exemplo de praticidade ao usuário da ferramenta, é busca por palavra-chave, que elimina o tempo necessário para uma busca com muitos filtros. O maior portal de busca do mundo, o Google.com, usa esta prática. Evidentemente, a busca por palavrachave é mais genérica podendo retornar resultado que não seja condizente com o desejado. Este modelo foi comentado anteriormente e está representado na Figura 4.

Mais especificamente, o modulo Cadastro de Anúncios foi desenvolvido segundo dois objetivos: ser prático e rápido. A Figura 7 apresenta como é o processo do cadastro de um anúncios, em quatro passos: $(i)$ Os dados para divulgação são compostos por fotos que serão apresentados em um slideshow e por um anexo com maiores informações sobre o evento; (ii) Os dados de endereço possuem a mesma funcionalidade demonstrada na Figura 6 (b), visando a consistência do endereço na busca por palavra-chave; (iii) Os dados do evento podem ser vistos como os mais essenciais desse processo, uma vez que é o motivo do usuário estar anunciando algo, nele são necessárias as informações técnicas do evento, tais como data, capacidade do local, duração do evento e valor; $(i v)$ Por fim são solicitados os dados de rastreamento, esses dados serão os primeiros a serem verificados em uma busca por palavra-chave, visando a busca otimizada.

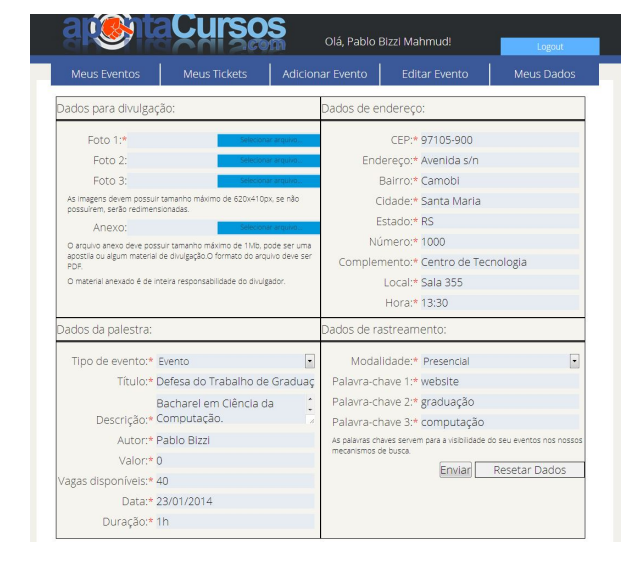

Figura 7. Layout da página de cadastro

\subsection{Eficiência das Buscas}

O principal objetivo, quando um sistema disponibiliza rotina de busca, é retornar dados relevantes e de forma mais eficiente. Contudo, na prática não é isto não é uma tarefa trivial. Para um sistema de buscas ser classificado como eficiente, ele deve atender às adversidades possíveis de ocorrer em uma consulta SQL.

Nos testes efetuados, o sistema apresentou respostas condizentes aos dados solicitados. Para atingir este objetivo, foram usadas construções complexas. Por exemplo, a consulta SQL usada na busca por palavra-chave possui um INNER JOIN e quatorze LEFT JOIN, contando ainda com vinte e duas verificações no WHERE. 


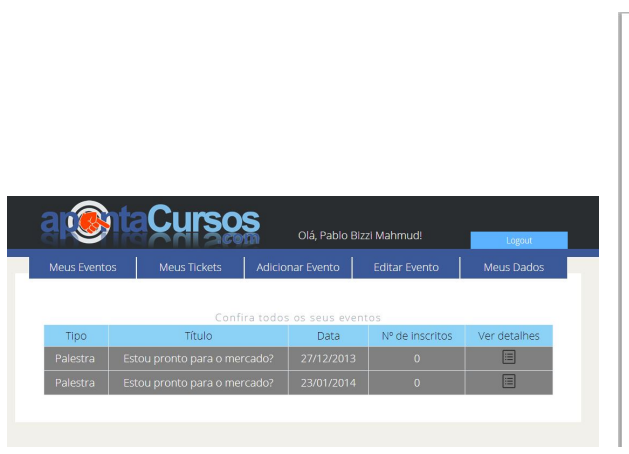

(a)

\section{apsntaCursos}

Lista de Presença - Aponta Cursos

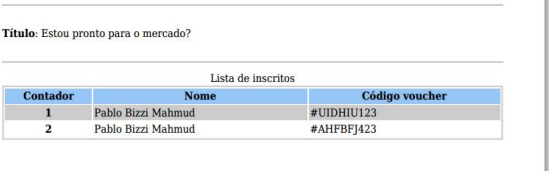

(b)

Figura 8. (a) Layout do painel dos anúncios do usuário e (b) Lista de inscritos gerada pelo anunciante com detalhamento.

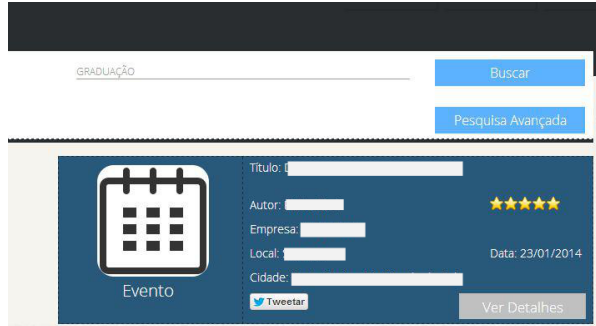

(a)

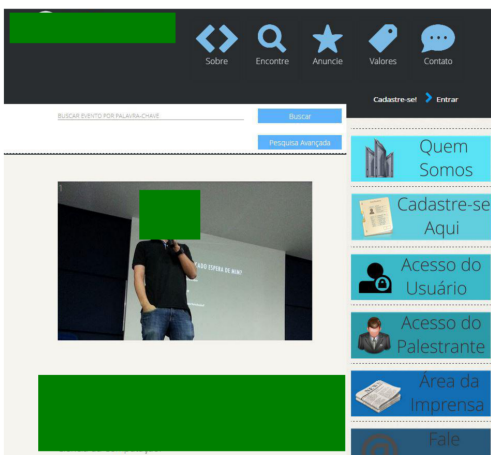

(b)

Figura 9. (a) Voucher que o usuário recebe em seu e-mail ao se inscrever em um evento e (b) Exemplo de página ao selecionar um anúncio.

\subsection{Apresentação de Conteúdo}

Em uma operação típica, um Anunciante, após incluir nova palestra, deseja saber da situação de cada um dos seus anúncios. A Figura 8 (a) representa um exemplo de primeira tela a qual usuário tem acesso quando entra com sua conta no sistema. A tela mostra o tipo de anúncio (Tipo), título, data, número de inscritos e apresenta a opção de detalhamento através de um link (Ver detalhes). A rotina de detalhes possibilita exportar um relatório em formato $p d f$ informando todos os usuários que se inscreveram no anúncio selecionado.

A seguir, se selecionada pelo usuário a opção Ver detalhes, como é apresentado na Figura 8 (b), esse relatório apresenta um contador para apresentar quantos inscritos o evento possui, o nome do inscrito e o código do voucher do comprador para a verificação da vericidade do mesmo.

Ao inscrever-se, o usuário recebe um voucher, o mesmo também é enviado por e-mail no ato da inscrição. Nele contém informações importantes como os dados do comprador, do anunciante e do evento.

Ao realizar uma busca no sistema, o usuário encontrará algo semelhante a Figura 9 (a), podendo visualizar o título, autor, empresa, local, cidade, data e a classificação do 


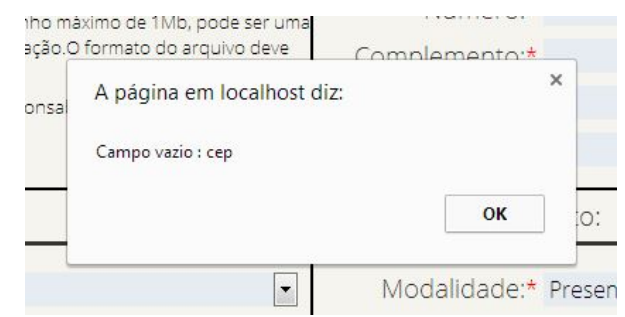

(a)

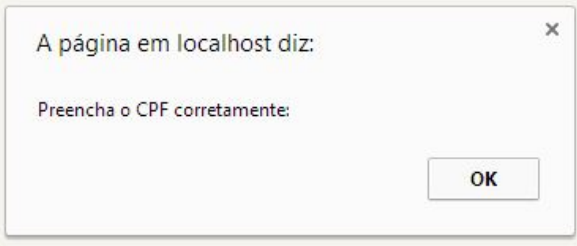

(b)

Figura 10. (a) Exemplo de erro de formulário incompleto e (b) Exemplo de erro de dados inválido.

anunciante. Se esse anúncio for selecionado, o usuário encontra uma página semelhante a qual a Figura 9 (b) apresenta. Através da análise dos questionários aplicados, foi decidido que o topo da página deveria ganhar destaque. Por esse motivo, a foto do evento aparece primeiro aos olhos do usuário. Os demais campos da página apresentam as informações do evento.

\subsection{Validação de Entrada de Informação}

Um grande desafio para um programador é desenvolver um sistema que evite a entrada de dados com erros. Nos testes realizados sobre a implementação atual do portal, não foi detectada nenhuma falha na validação de informações de entrada, sejam textos, anexos ou imagens.

A Figura 10 representa caixas de diálogo que o sistema apresenta ao usuário quando o mesmo tenta submeter um formulário com erros. $\mathrm{O}$ erro foi causado pelo fato do usuário não ter digitado o CEP. O descaso com essa informação poderia ressaltar em uma falha de aplicação onde um usuário nunca saberia o local onde ocorrerá o evento, o comprador opta por não realizar a inscrição e o anunciante perde um possível inscrito.

Na Figura 10 (b), o erro foi causado pela digitação errônea da informação para verificar a veracidade do usuário. Uma vez que o usuário falsifica um CPF para realizar o cadastro no sistema, admite-se que ele pode fraudar diversos anúncios e lesar diversos usuários. Dificultar o processo para um usuário indesejado ser cadastrado no sistema, resulta em um sistema mais seguro e confiável.

As principais rotinas de tratamento de erros do sistema são: $(i)$ Validação do email; (ii) Verificação do número de caracteres da senha; (iii) No inputfile de imagens é verificado se a extensão do arquivo é de uma imagem; (iv) No inputfile de anexo é verificado se a extensão do arquivo é de um anexo; e $(v)$ Verificação de CPF e CNPJ.

\section{Conclusões e Trabalhos Futuros}

O mercado de trabalhado está cada vez mais competitivo, trazendo a necessidade da busca por qualificação de profissionais que visam a especialização, sendo motivado ainda pelo advento de novas tecnologias no que se refere a portais de centralização de informação. Agregando o fato de, por exemplo, não existir no mercado um website onde um usuário que deseja capacitação consiga encontrar as devidas informações para um curso na sua região, justificou-se a oportunidade de desenvolver o apontaCursos.

Para este trabalho, foram buscados métodos eficazes para coletar requisitos, funcionalidades e necessidades. Nesse contexto, foram utilizados métodos propostos por [4], 
adaptando-os às necessidades do sistema proposto. Os resultados almejados deste processo foram obtidos. A ferramenta resultante apresenta um novo panorama no que se diz respeito a portais de centralização de informação voltados à educação e à qualificação de pessoal.

Após a conclusão do processo de desenvolvimento deste projeto, a implementação foi iniciada. Para tanto, foram escolhidas tecnologias e ferramentas para compor o sistema no seu processo de desenvolvimento, garantindo um projeto e um produto organizado e padronizado.

As avaliações da ferramenta foram de caráter subjetivo e de observações feitas por colaboradores do Laboratório de Sistemas de Computação da UFSM. A medida que foram detectados erros ou uma manutenção necessária, foram realizadas as devidas alterações, resultando na evolução e adaptação do sistema atual.

Com a disponibilidade desta ferramenta para o público em geral, espera-se obter diversos feedbacks dos usuários, caso seja necessário, o sistema pode ser adaptado às novas exigências, seja de mercado ou de funcionalidades.

Finalmente, pode ser concluido que avaliar as funcionalidades de um sistema não é algo trivial: as mudanças que podem acontecer em sua interface ou em suas rotinas geram novas demandas de desenvolvimento, as quais geram novas demandas de validação.

Todas as sugestões de alterações para este sistema abrem novos caminhos para estabelecer continuidade a investigações futuras, que envolvem usabilidade, funcionalidades específicas e praticidade do sistema, transformando este trabalho em uma ferramenta que auxilie cada vez mais seus usuários. Mais especificamente, em um novo processo de avaliação de necessidade e funcionalidade, podem ser delimitados os seguintes trabalhos futuros: desenvolvimento de funções para tratar carrinho de compras, cadastro de palestras em wizard, criação de lotes nos tickets dos eventos, reaproveitamento de um evento anterior, novas avaliações do sistema e sua distribuição ao público.

\section{Referências}

[1] S. Brin, L. Page. Reprint of: The anatomy of a large-scale hypertextual web search engine. In: Computer networks, Volume 56. Elsevier Science Publishers B. V., Amsterdam, The Netherlands, 2012. pp. 3825-3833.

[2] J. Nielsen; D. A. Norman. Web-Site Usability: Usability On The Web Isn't A Luxury. Information Week, 2000.

[3] R. Schulenburg, M. Ramos Pezzini. Sistematização de conceitos ergonômicos e semióticos para projetos de interfaces gráficas do usuário. In: Projética, Londrina/PR - Brasil, ISSN: 2236-2207 v. 4, n. 1, 2013, pp. 119-218.

[4] I. Sommerville. Engenharia de Software. 8a. Edição. [S.1.]: São Paulo: Pearson AddisonWesley, 2007.

[5] E. Goulart, A. Junior. Pesquisas na web: estratégias de busca. Revista Digital de Biblioteconomia e Ciencia da Informação, Volume 4, 2007. pp. 53-66. 